\title{
Close Association of Regional Interleukin-6 Levels in the Infarct-Related Culprit Coronary Artery With Restenosis in Acute Myocardial Infarction
}

\author{
Hiroshi Funayama, MD; San-e Ishikawa, MD; Norifumi Kubo, MD; \\ Takanori Yasu, MD; Muneyasu Saito, MD; Masanobu Kawakami, MD
}

\begin{abstract}
Background The involvement of interleukin (IL)-6 in restenosis of the recanalized coronary artery after the percutaneous coronary intervention (PCI) was examined.

Methods and Results There were 40 patients enrolled in the study who had acute myocardial infarction and whose infarct-related coronary arteries were treated by new thrombectomy devices and stenting. Blood samples were collected from the culprit coronary artery before and immediately after the maneuver of the PCI. Restenosis was defined as residural stenosis because it accounted for more than $50 \%$ at the follow-up coronary angiography. Plasma IL-6 levels in the infarct-related coronary artery were 12.8 and $13.2 \mathrm{pg} / \mathrm{ml}$ before and after the initial maneuver of the PCI, respectively, values that were significantly greater than that of $7.2 \mathrm{pg} / \mathrm{ml}$ in the peripheral vein $(\mathrm{p}<0.0001)$. The levels of IL-6 in the pre- and the post-stage of PCI were significantly greater in the patients with restenosis than those without restenosis. The plasma IL-6 levels in the post-stage of PCI had significant correlations with late loss and loss index.

Conclusions The present study findings indicate that plasma IL-6 levels in the culprit coronary artery at the post-stage of PCI are closely associated with the future restenosis of the revasculized coronary artery in acute myocardial infarction. (Circ J 2006; 70: 426-429)
\end{abstract}

Key Words: Acute myocardial infarction; Interleukin-6; Restenosis

$\mathbf{V}$

ulnerable fibrous caps of atherosclerotic plaque are suggested to be involved in an acute occlusion of the coronary artery in acute myocardial infarction. ${ }^{-4}$ The in vivo studies in experimental animals with atherosclerotic plaques indicate that interleukin (IL)- $1 \beta$, IL6 and tumor necrosis factor- $\alpha$ may be released from the vulnerable plaques ${ }^{5-6}$ We demonstrated an increase in regional IL-6 levels in the infarct-related coronary artery in patients with acute myocardial infarction? Recent development of the percutaneous coronary intervention (PCI) technique enables us to rescue patients from acute coronary occlusion?-10 However, one of the residual problems is restenosis of the coronary artery, which was recanalized by PCI. If regional cytokines would deteriorate the restenosis, the measurement of IL-6 level in the infarct-related coronary artery might be a useful tool for the risk of restenosis after PCI.

In the present study, we determined the IL- 6 levels in the infarct-related coronary artery, and furthermore investigated whether the IL-6 level is associated with the reccurrence of stenosis 6 months after the treatment of PCI in patients with acute myocardial infarction.

\section{Methods}

\section{Subjects}

Forty patients with acute myocardial infarction and who

(Received April 20, 2005; revised manuscript received January 5, 2006; accepted January 27, 2006)

Department of Medicine, Jichi Medical School, Omiya Medical Center, Saitama, Japan

Mailing address: Hiroshi Funayama, MD, Department of Medicine, Jichi Medical School, Omiya Medical Center, Saitama 330-8503,

Japan. E-mail: funahiro@omiya.jichi.ac.jp were who were admitted to the Emergency Units of Jichi Medical School Omiya Medical Center were enrolled between April 2001 and March 2002. There were 34 males and 6 females whose ages ranged from 37 to 76 years $(59.8 \pm 9.8$ years, mean $\pm \mathrm{SD})$. The diagnosis of acute myocardial infarction was determined by the findings of continuous chest pain more than $30 \mathrm{~min}$, ST-segment elevation greater than $2.0 \mathrm{~mm}$ on at least 2 successive ECG leads, and more than a 2 -fold increase in serum creatine kinase (CK) levels. In all patients, cardiac catheterization was carried out within $24 \mathrm{~h}$ after the onsets of myocardial infarction and a follow-up angiography was performed 6 months after the initial catheterization. Criteria for the patient enrolment were as follows: (1) within $24 \mathrm{~h}$ after the onset; (2) single vessel disease; and (3) a proximal lesion of the coronary artery. Anterior myocardial infarction was found in 25 patients, lateral myocardial infarction was in 4 patients, and inferior myocardial infarction was found in 11 patients. Coronary risk factors were obtained in a majority of patients; that is, 23 patients had diabetes mellitus, 28 patients had hypertension, 24 patients had hyperlipidemia, 23 patients had obesity, and 20 patients were current smokers. We excluded the patients with cardiogenic shock, those with chronic renal failure on hemodialysis, those with an apparent infectious disease, those with bypass failure, those with prior use of thrombolytic therapy, and those with an inability to cross the target lesion with a thrombectomy catheter because of excessive proximal vessel tortuosity from the study. Maximal levels of serum CK ranged from 262.0 to $8,648.0 \mathrm{mU} / \mathrm{ml}(3,099.6 \pm 20,145.8 \mathrm{mU} / \mathrm{ml}$, mean $\pm \mathrm{SD})$.

\footnotetext{
Study Protocol

Blood samples were collected from the peripheral vein
} 
Table 1 Clinical, Angiographic and Procedural Characteristics in Patients With Acute Myocardial Infarction

\begin{tabular}{|c|c|c|c|}
\hline & $\begin{array}{c}\text { No restenosis } \\
\quad(n=26)\end{array}$ & $\begin{array}{l}\text { Restenosis } \\
\quad(n=14)\end{array}$ & $p$ value \\
\hline Age, years & $59.5 \pm 2.1$ & $60.5 \pm 2.3$ & 0.75 \\
\hline$M / F$ & $21 / 5$ & $13 / 1$ & 0.31 \\
\hline \multicolumn{4}{|l|}{ Coronary risk factors } \\
\hline Hypertension (n) & 19 & 9 & 0.56 \\
\hline Diabetes mellitus ( $n$ ) & 15 & 8 & 0.97 \\
\hline Hyperlipidemia (n) & 17 & 7 & 0.34 \\
\hline Current smoker (n) & 20 & 5 & 0.39 \\
\hline Time until the procedure of $P C I(h)$ & $6.5 \pm 0.8$ & $8.4 \pm 1.3$ & 0.19 \\
\hline Peak $C K(I U / m l)$ & $3,626.6 \pm 472.1$ & $2,766.4 \pm 439.3$ & 0.13 \\
\hline Ejection fraction at admission (\%) & $53.0 \pm 2.1$ & $47.9 \pm 2.9$ & 0.89 \\
\hline Culprit vessel (LAD/LCX/RCA) (n) & $16 / 3 / 7$ & 9/1/4 & 0.91 \\
\hline Type of stent (NIR/Multi-link/S670) & $5 / 14 / 7$ & $5 / 6 / 3$ & 0.52 \\
\hline Stent length $(\mathrm{mm})$ & $16.65 \pm 0.60$ & $15.00 \pm 0.89$ & 0.12 \\
\hline Maximal inflation pressure (atm) & $12.4 \pm 0.5$ & $13.6 \pm 0.8$ & 0.15 \\
\hline Duration of inflation $(s)$ & $51.0 \pm 1.5$ & $56.8 \pm 6.4$ & 0.26 \\
\hline Reference diameter $(\mathrm{mm})$ & $3.09 \pm 0.08$ & $3.12 \pm 0.14$ & 0.81 \\
\hline \multicolumn{4}{|l|}{ After PCI } \\
\hline$M L D(\mathrm{~mm})$ & $2.62 \pm 0.07$ & $2.51 \pm 0.15$ & 0.45 \\
\hline Residual stenosis (\%) & $14.8 \pm 1.5$ & $19.8 \pm 3.6$ & 0.14 \\
\hline \multicolumn{4}{|l|}{ Follow-up angiography } \\
\hline$M L D(\mathrm{~mm})$ & $2.56 \pm 0.41$ & $0.99 \pm 0.15$ & $<0.01$ \\
\hline Residual stenosis (\%) & $29.7 \pm 2.4$ & $66.8 \pm 4.8$ & $<0.0001$ \\
\hline Late loss $(\mathrm{mm})$ & $0.45 \pm 0.07$ & $1.41 \pm 0.12$ & $<0.0001$ \\
\hline Loss index & $0.18 \pm 0.03$ & $0.56 \pm 0.05$ & $<0.0001$ \\
\hline \multicolumn{4}{|l|}{ Medications } \\
\hline Statin at admission ( $n$ ) & 4 & 3 & 0.63 \\
\hline Statin at follow up (n) & 20 & 11 & 0.91 \\
\hline ACEI at follow up ( $n$ ) & 22 & 12 & 0.93 \\
\hline
\end{tabular}

Values are expressed as mean \pm SEM or number of patients.

$P C I$, percutaneous coronary intervention; CK, creatine kinase; LAD, left anterior descending artery; LCX, left circumflex artery; $R C A$, right coronary artery; $M L D$, minimum lumen diameter; ACEI, angiotensin-converting enzyme inhibitor.

and the occluded coronary vessel before and immediately after the maneuver of PCI by the thrombectomy catheter to measure plasma IL-6. Briefly, heparin (10,000 IU) was administered intravenously, and $162 \mathrm{mg}$ of aspirin was given orally. A coronary angiography was performed using a catheter via the femoral approach. A thrombectomy catheter (RESCUE thrombectomy catheter, SciMED/BSC, Inc, Maple Grove, MN, USA) was introduced through the guiding catheter:-10 After thrombectomy, direct stenting was carried out. Blood samples were collected by gentle sucking from the occluded site of the culprit coronary artery again immediately after the maneuver of the PCI. After PCI, the patients were treated with $81 \mathrm{mg} /$ day aspirin and $200 \mathrm{mg} /$ day ticlopidine for 1 month.

A follow-up coronary angiography was carried out 6 months after PCI to determine the reccurrence of stenosis. Restenosis is defined as residual stenosis being more than $50 \%$ at the follow-up coronary angiography stage ${ }^{11}$ If restenosis was diagnosed, coronary intervention was conducted. The patients were divided into 2 groups; with and without restenosis. The present study was approved by the Ethical Committee of Jichi Medical School. We obtained written informed consent from all the patients before coronary angiography was performed.

\section{Measurements}

Blood was collected in chilled tubes containing EDTA$\mathrm{Na} 2\left(1 \mathrm{mg} / \mathrm{ml}\right.$ blood) and centrifuged at $3,000 \mathrm{rpm}$ at $4{ }^{\circ} \mathrm{C}$ for $15 \mathrm{~min}$. The supernatants were decanted and frozen at $-80^{\circ} \mathrm{C}$ until the time of assay for plasma IL-6. Plasma IL-6 was determined by an ELISA using Quantikine human IL6 assay kits (R\&D system, Minneapolis, MN, USA)!1 The minimal detectable concentration of IL-6 was $0.70 \mathrm{pg} / \mathrm{ml}$. Intra- and interassay coefficients of variation were 2.6 and $4.5 \%$, respectively.

\section{Quantitative Coronary Angiography Analysis}

A computer-based quantitative coronary angiography analysis software designed by GE Medical System (Milwaukee, WI, USA) was used. The measurements were performed on the end-diastolic frames by a single investigator who was blinded to the study results. A reference diameter, lesion length, and minimum lumen diameter (MLD) were measured before and after the angioplasty and at the time of the follow-up angiography. We determined the acute gain (MLD after the angioplasty minus MLD before the angioplasty), the late loss (MLD after the angioplasty minus MLD at follow-up angiography), and the late loss index (the average ratio of late loss to acute gain). A value of $0 \mathrm{~mm}$ was assigned for MLD in the case of total occlusion at base line.

\section{Statistical Analysis}

All values were expressed as mean \pm SEM. Comparisons between the 2 groups were analyzed by using the unpaired Student's t-test. Differences in the distribution of variables were analyzed by using the chi-square test. Simple linear regression analysis was performed to calculate correlations. A p value less than 0.05 was considered significant.

\section{Results}

Table 1 summarizes the clinical characteristics of patients with acute myocardial infarction. The patients were 
A

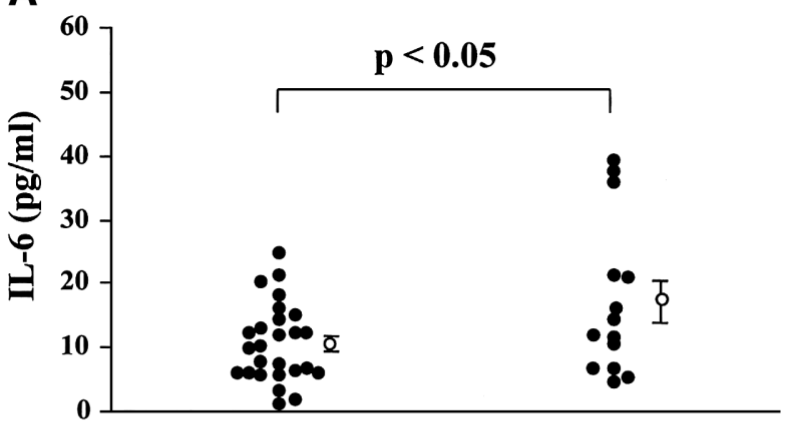

B

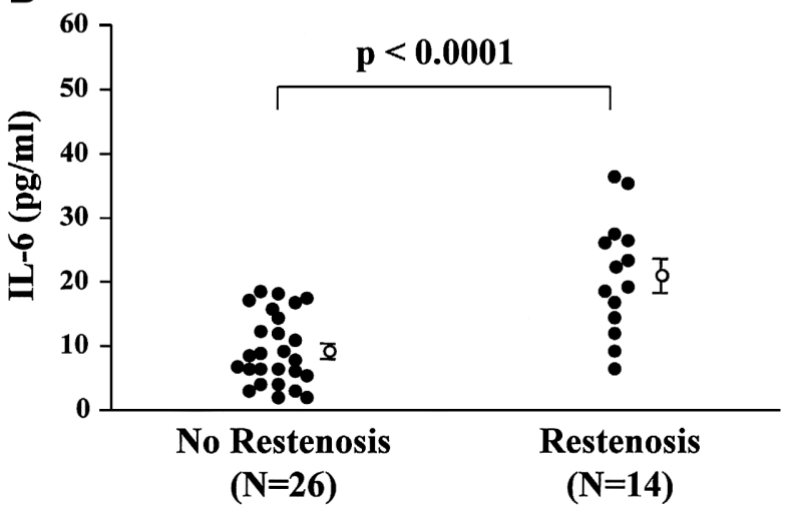

Fig 1. Plasma interleukin (IL)-6 levels in culprit coronary artery before (A) or after (B) the maneuver of percutaneous coronary intervention in patients with acute myocardial infarction in the presence and absence of restenosis. Open circles indicateds mean \pm SEM values.

divided into 2 groups; with and without restenosis, by determining recanalization 6 months after the PCI. There were no differences in age, sex, coronary risk factors and lesion characteristics between the 2 groups. During the initial maneuver of PCI, residural stenosis was $19.8 \pm 3.6 \%$ and $14.8 \pm 1.5 \%$ in patients with and without restenosis, respectively. A follow-up angiography clearly showed that the residural stenosis was $66.8 \pm 4.8 \%$ in the patients with restenosis; a value significantly greater than that of $29.7 \pm$ $2.4 \%$ in those without restenosis $(\mathrm{p}<0.0001)$. Both the late loss and loss indexs were significantly greater in patients with restenosis than those without restenosis.

Plasma IL-6 levels in the infarct-related coronary artery were $12.8 \pm 1.4$ and $13.2 \pm 1.4 \mathrm{pg} / \mathrm{ml}$ before and after the initial maneuver of PCI, respectively, which was significantly higher than that of $7.2 \pm 1.0 \mathrm{pg} / \mathrm{ml}$ in the peripheral vein $(\mathrm{p}<0.0001)$. The regional IL-6 levels after PCI in the infarct-related coronary artery positively correlated with those before the PCI $(r=0.61, p<0.0001)$. When plasma IL6 levels were compared between the presence and absence of restenosis, the difference in plasma IL-6 levels in the culprit coronary artery was evident; that is, plasma IL-6 levels before and after the PCI were significantly greater in patients with restenosis than those without restenosis (Fig 1$)$. The higher significance $(\mathrm{p}<0.0001)$ was obtained with the values after PCI. In addition, it is evident that in those patients without restenosis, the plasma IL-6 levels in the infarct-related coronary artery were $10.5 \pm 1.2$ and $9.1 \pm$ $1.1 \mathrm{pg} / \mathrm{ml}$ before and after PCI, respectively; values that were still greater than that of $6.6 \pm 1.0 \mathrm{pg} / \mathrm{ml}$ found in the peripheral vein $(\mathrm{p}<0.05)$. There was no difference in

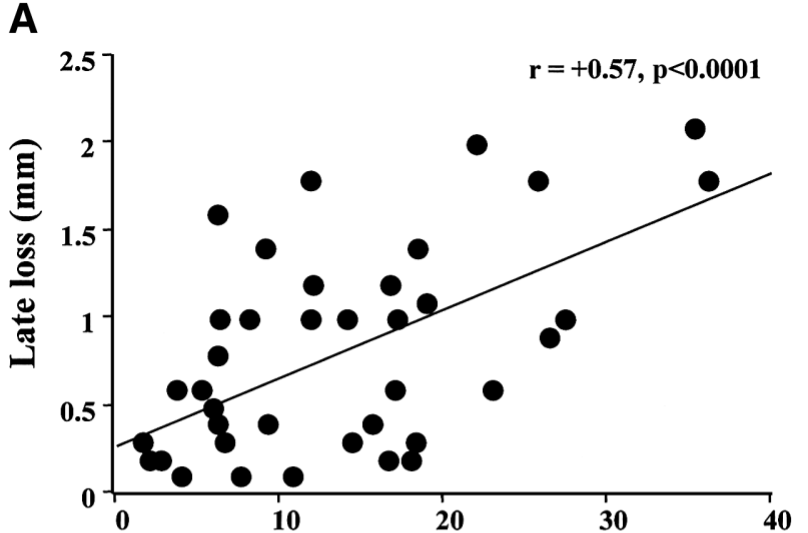

B

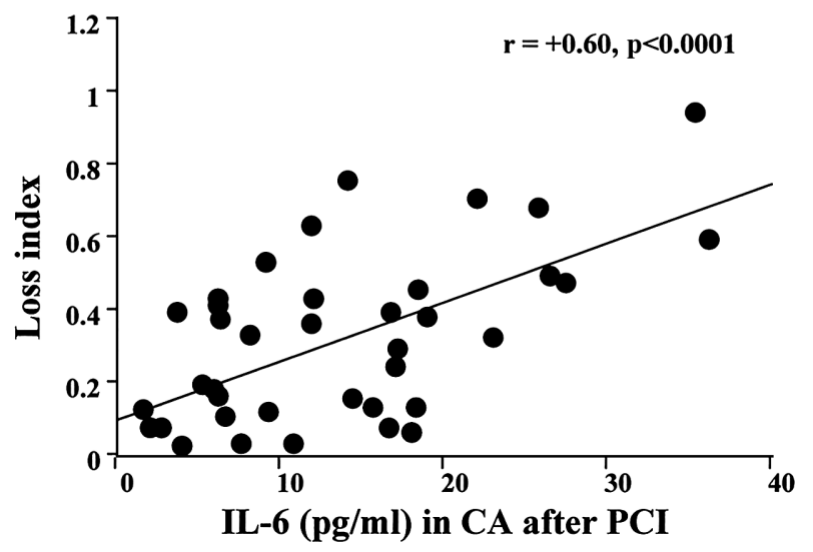

Fig 2. Relationship between plasma interleukin (IL)-6 levels in the infarct-related coronary artery (CA) after percutaneous coronary intervention (PCI) with late loss (A) and late loss index (B) in the patients with acute myocardial infarction.

plasma IL-6 levels in the peripheral vein between patients with and without restnosis $(8.3 \pm 2.2$ vs $6.5 \pm 1.0 \mathrm{pg} / \mathrm{ml}$, $\mathrm{p}=0.42$ ). Plasma IL-6 levels in the peripheral vein did not correlate with the maximal level of $\mathrm{CK}(\mathrm{r}=0.28, \mathrm{p}=0.09)$ and ejection fraction $(\mathrm{r}=-0.16, \mathrm{p}=0.36)$ (data not shown).

As shown in Fig 2, late loss had a positive correlation with plasma IL-6 levels in the culprit coronary artery after PCI in patients with myocardial infarction $(r=0.57, \mathrm{p}<$ $0.0001)$. A similar result was obtained between the late loss index and plasma IL-6 levels in the culprit coronary artery after PCI $(\mathrm{r}=0.60, \mathrm{p}<0.0001)$.

\section{Discussion}

The present study demonstrated an increase in regional IL-6 levels in the infarct-related coronary artery before and after PCI in patients with acute myocardial infarction. In particular, restenosis was found to be prominent in patients whose regional IL-6 levels after PCI were elevated.

In our previous study, the inflammatory cytokine IL-6 is increased in the infarct-related coronary artery in the patients with acute myocardial infarction? IL-6 could be synthesized by activated macrophages and with vascular smooth muscle cells infiltrating into the atherosclerotic plaque $!^{2-16}$ Mechanical stretch, vascular injury and hypoxia may be involved in causing IL-6 release in the coronary circulation after PCI. The increase in regional IL-6 levels may facilitate the process of breakdown of the vulnerable 
region of atherosclerotic plaque by activating macrophages. Macrophages secret proteolytic enzymes such as metalloproteinases, which can break down both collagen and elastin to peptides and eventually amino acids ${ }^{17-20}$ The regional IL-6 levels are associated with the size of the fragile plaque itself. The present study did not evaluate the quality of plaque, but instead evaluated the fibrous plaque, which should be fragile.

We found that the regional IL-6 levels after PCI in the infarct-related coronary artery positively correlated with those before PCI. Furthermore, the regional IL-6 levels after PCI were strongly associated with restenosis of the recanaled coronary artery. In contrast, there was no difference in plasma IL-6 levels in the peripheral vein between the patients with and without restenosis. Recently, Suzuki et al found that in patients with stable angina pectoris, plasma IL-6 levels in the peripheral vein were significantly greater 1 and $6 \mathrm{~h}$ after the maneuver of PCI in the group with restenosis compared with the group without restenosis. $^{21}$ Also, there was a significant correlation between changes in IL-6 levels in the coronary circulation after PCI and the degree of angiographic restenosis in the patients with stable angina pectoris 22 In the present study, we enrolled the patients with acute myocardial infarction. Plasma IL-6 levels in the patients' peripheral vein could be linked to total systemic inflammation, which is not only related to the culprit coronary artery, but also with necrosis of the myocardium.

An enhanced expression of cytokines is suggested to be involved in acute and chronic complications of PCI by causing the release of vasoactive substances and other growth factors, and thereby establishing a positive autocrine and paracrine feedback loop - a "cascade mechanism"?3 IL6 is a multifunctional cytokine, regulating humoral and cellular responses and it plays a central role in inflammation and tissue injury. IL-6 has procoagulant properties ${ }^{24-26}$ and mitogenic activity for smooth muscle cells? ${ }^{27}$ The alteration in regional IL-6 does not only include the present inflammation of the recanaled artery, but also the size and fragility of fibrous atherosclerotic plaque.

In conclusion, the measurement of plasma IL-6 in the infarct-related coronary artery at PCI is associated with future restenosis in patients with acute myocardial infarction. In particular, the regional IL-6 level after PCI is an excellent indicator for restenosis.

\section{Study Limitations}

The present study did not include any patients with stable angina pectoris, and our findings are only related to patients with acute myocardial infarction. The patient population was relatively small and further studies with larger numbers of patients are required to prove our hypothesis.

\section{Acknowledgments}

The present study was supported by a grant from the Ministry of Education, Science and Culture of Japan (No.14770327). We thank Drs Tomohiro Nakamura, Takuji Katayama, Takamasa Iwasawa, Shigemasa Hashimoto, Yoshio Tsuruya and Mikihisa Fujii for their technical support during the cardiac catheterization.

\section{References}

1. Ross R. Atherosclerosis: An inflammatory disease. $N$ Engl J Med 1999; 340: 115-126.

2. Fuster V, Badimon L, Badimon J, Chesebro JH. The pathogenesis of coronary artery disease and the acute coronary syndromes. $N$ Eng $J$
Med 1992; 326: 242-250.

3. Blake GJ, Ridker PM. Novel clinical markers of vascular wall inflammation. Circ Res 2001; 89: 763-771.

4. Libby P, Ridker PM, Maseri A. Inflammation and atherosclerosis. Circulation 2002; 105: 1135-1143.

5. Ikeda U, Ikeda M, Seino Y, Takahashi M, Kano S, Shimada K. Interleukin 6 gene transcripts are expressed in atherosclerotic lesions of genetically hyperlipidemic rabbits. Atherosclerosis 1992; 92: $213-$ 218.

6. Clinton S, Fleet JC, Loppnow H, Salomon RN, Clark BD, Cannon JG, et al. Interleukin-1 gene expression in rabbit vascular tissue in vivo. Am J Pathol 1991; 138: 1005-1014.

7. Funayama H, Ishikawa S, Kubo N, Katayama T, Yasu T, Saito M, et al. Increases in interleukin-6 and matrix metalloproteinase-9 in the infarct-related coronary artery of acute myocardial infarction. Circ J 2004; 68: $451-454$.

8. van Omemen V, Michels R, Heymen E, van Asseldonk, Bonow H, Vainer J, et al. Usefulness of the rescue PT catheter to remove fresh thrombus from coronary arteries and bypass grafts in acute myocardial infarction. Am J Cardiol 2001; 88: 306-308.

9. Kotani J, Nanto S, Mintz GS, Kitakaze M, Ohara T, Morozumi T, et al. Plaque gruel of atheromatous coronary lesion may contribute to the no-reflow phenomenon in patients with acute coronary syndrome. Circulation 2002; 106: 1672-1677.

10. Nakamura T, Kubo N, Seki Y, Ikeda N, Ishida T, Funayama H, et al. Effects of distal protection device during primary stenting in patients with acute anterior myocardial infarction. Circ J 2004; 68: 763-768.

11. Bourassa MG, Alderman EL, Bertand M, de la Fuente L, Gratsianski A, Kaltenbach M, et al. Report of joint ISFC/WHO Task Force on coronary angioplasty. Circulation 1988; 78: 780-789.

12. Kato K, Matsubara T, Iida K, Suzuki O, Sato Y. Elevated levels of pro-inflammatory cytokines in coronary artery thrombi. Int J Cardiol 1999; 70: $267-273$.

13. Rus HG, Vlaicu R, Niculescu F. Interleukin-6 and interleukin-8 protein and gene expression in human arterial atherosclerotic wall. Atherosclerosis 1996; 127: 263-271.

14. Seino Y, Ikeda U, Ikeda M, Yamamoto K, Misawa Y, Hasegawa T, et al. Interleukin 6 gene transcripts are expressed in human atherosclerotic lesions. Cytokine 1994; 6: 87-91.

15. Schieffer B, Schieffer E, Hifiker-Kleiner D, Hilfiker A, Kovanen PT, Kaartnen M, et al. Expression of angiotensin II and interleukin-6 in human coronary atherosclerotic plaques. Circulation 2000; 101: $1372-1378$.

16. Ikeda U, Ito T, Shimada K. Interleukin-6 and acute coronary syndrome. Clin Cardiol 2001; 24: 701-704.

17. Libby P. Molecular bases of the acute coronary syndrome. Circulation 1995; 91: 2844-2850.

18. Shah PK, Falk E, Badimon JJ, Fernandez-Ortiz A, Maihac A, Villareal-Levy G, et al. Human monocyte-derived macrophages induce collagen breakdown in fibrous caps of atherosclerosis plaque: Potential role of matrix-degrading metalloproteinases and implications for plaque rupture. Circulation 1995; 92: 1565-1569.

19. Libby P, Geng YJ, Aikawa M, Schoenbeck U, Mach F, Clinton SK, et al. Macrophages and atherosclerotic plaque stability. Curr Opin Lipidol 1996; 7: 330-335.

20. Lippy P. Current concepts of the pathogenesis of acute coronary syndrome. Circulation 2001; 104: 365-375.

21. Suzuki T, Ishiwata S, Hasegawa K, Yamamoto K, Yazaki T. Raised interleukin 6 concentrations as a predictor of postangioplasty restenosis. Heart 2000; 83: 578 .

22. Hojo Y, Ikeda U, Katsuki T, Mizuno O, Fukazawa H, Kurosaki K, et al. Interleukin 6 expression in coronary circulation after coronary angioplasty as a risk factor restenosis. Heart 2000; 84: 83-87.

23. Lippy P, Schwartz D, Brogi E, Tanaka H, Clinton SK. A cascade model for restenosis: A special case of atherosclerosis progression. Circulation 1992; 86(Suppl III): IIII-47-III-52.

24. Mestries JC, Kruithof EKO, Gascon MP, Herodin F, Agay D, Ythier A. In vivo modulation of coagulation and fibrinolysis by recombinant glycosilated human interleukin-6 in baboons. Eur Cytokine Netw 1994; 5: 275-281.

25. van der Poll T, Levi M, Hack CE, ten Cate H, van Deventer SJ, Eerenberg AJ, et al. Elimination of interleukin-6 attenuates coagulation activation in experimental endotoxemia in chimpanzees. $J$ Exp Med 1994; 179: 1253-1259.

26. Stouthard JML, Levi M, Hack CE, veenhof $\mathrm{CH}$, Romijn HA, Sauerwien HP, et al. Interleukin-6 stimulates coagulation, not fibrinolysis, in humans. Thromb Haemost 1996; 94: 874-877.

27. Ikeda U, Ikeda M, Oohara T, Oguchi A, Kamitani T, Tsuruya Y, et al. Interleukin-6 stimulates the growth of vascular cells in a PDGF dependent manner. Am J Physiol 1991; 260: H1713-H1717. 